\title{
Triterpenoid saponins from Aesculus sylvatica W. Bartram
}

\author{
Wei Yuan ${ }^{1}$, Ping Wang ${ }^{1}$, Zushang $\mathrm{Su}^{1}$, Ruixin Gao ${ }^{1,2}$, Shiyou $\mathrm{Li}^{1 *}$ \\ ${ }^{1}$ National Center for Pharmaceutical Crops, Arthur Temple College of Forestry and \\ Agriculture, Stephen F. Austin State University, Nacogdoches, TX 75962-6109, USA \\ ${ }^{2}$ College of Life Science, Northeast Forestry University, 26 Hexing Road, Harbin, Heilongjiang \\ 150040, China \\ * Tel.: +1 936-468-2071; fax: +1 936-468-7058. E-mail address: lis@sfasu.edu (S. Li)
}




\section{ABSTRACT}

16 triterpenoid saponins including two new compounds were isolated from the seeds of Aesculus sylvatica W. Bartram. The two new saponins were assigned as 3-O-[ $\beta-\mathrm{D}-$ glucopyranosyl-( $(\rightarrow 2)]$ - $\alpha$-L-arabinofuranosyl-(1 $\rightarrow 3)-\beta$-D-glucuronopyranosyl-21,22-O-

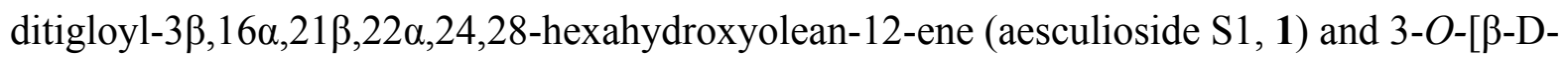
glucopyranosyl-( $1 \rightarrow 2)$ ]- $\alpha$-L-arabinofuranosyl-( $1 \rightarrow 3)$ - $\beta$-D-glucuronopyranosyl-21-O-tigloyl-22$O$-angeloyl-3 $\beta, 16 \alpha, 21 \beta, 22 \alpha, 24,28$-hexahydroxyolean-12-ene (aesculioside S2, 2). Aesculioside S1 and S2 displayed moderate cytotoxicity against human non-small cell lung cancer cells (A549) and prostate cancer cells (PC3) $\left(\mathrm{GI}_{50}\right.$ ranged from 8.7 to $\left.18.2 \mu \mathrm{M}\right)$. The structural analysis of the saponins isolated from Aesculus supports the taxonomic placement of $A$. sylvatica under the section Pavia of Aesculus genus.

Keywords:

Aesculus sylvatica;

Painted buckeye;

Triterpenoid saponins;

Cytotoxicity;

Chemotaxonomy. 


\section{Introduction}

Aesculus L. is a genus of Sapindaceae with 12 shrub or small deciduous tree species in the northern hemisphere (Zhang et al., 2010). As a remarkable example of an intercontinental disjunction genus, the taxonomy, biogeography, and evolution of Aesculus have attracted great attention from botanists (Harris and Xiang, 2009; Harris et al., 2009; Modliszewski et al., 2006;

Xiang et al., 1998). The phylogenetic and biogeographic analysis of Aesculus was made using molecular and morphological data with some controversial results (Harris et al., 2009; Xiang et al., 1998). Since 2004, we have conducted extensive phytochemical investigations of North America Aesculus species to identify bioactive saponins against human cancer (Yuan et al., 2012; Yuan et al., 2013; Zhang and Li, 2007; Zhang et al., 2010; Zhang et al., 2006). 61 polyhydroxyoleanene saponins including 56 previously unknown compounds were reported from A. pavia L. and A. glabra Willd. distributed in eastern North America and A. californica (Spach) Nutt. distributed in western North America. The phytochemical data of these Aesculus species formed a basis for medical uses of Aesculus and its triterpenoid saponins and provided new evidences for understanding systematics and evolutionary pattern of the genus. In the present study, we report 16 triterpenoid saponins isolated from Aesculus sylvatica W. Bartram (commonly known as painted buckeye), another species of Aesculus in the southeastern USA.

\section{Results and discussion}

From $400 \mathrm{~g}$ A. sylvatica seeds, two new oleanane saponins (1-2) together with 14 known saponins (3-16) were isolated (Fig. 1). By analysis of their NMR spectral data, the known saponins were identified as aesculioside IIe (3) (Zhang and Li, 2007), aesculioside IIf (Zhang and Li, 2007), aesculioside IIg (5) (Zhang and Li, 2007), aesculioside IIh (6) (Zhang and 
Li, 2007), aesculioside IIk (7) (Zhang and Li, 2007), aesculioside IIj (8) (Zhang and Li, 2007), aesculioside IIId (9) (Zhang and Li, 2007), aesculioside IIIe (10) (Zhang and Li, 2007), aesculioside IIIf (11) (Zhang and Li, 2007), aesculioside G6 (12) (Yuan et al., 2012), xanifoliaY8 (13) (Chan et al., 2008; Voutquenne et al., 2005), aesculioside G9 (14) (Yuan et al., 2012), aesculioside G10 (15) (Yuan et al., 2012), and xanifolia-Y10 (16) (Voutquenne et al., 2005). Known saponins 3 11 were previously reported in A. pavia (Zhang et al., 2006). 12, 14 and 15 were reported in A. glabra (Yuan et al., 2012). 13 was reported from A. pavia, A. glabra, Xanthoceras sorbifolia, and Harpullia austro-caledonica (Chan et al., 2008; Voutquenne et al., 2005; Yuan et al., 2012; Zhang et al., 2006). 16 was reported from A. pavia, X. sorbifolia, and H. austro-caledonica (Chan et al., 2008; Voutquenne et al., 2005; Yuan et al., 2012; Zhang et al., 2006). The structures of the two new saponins (1-2) were elucidated by extensive analysis of their spectroscopic data as well as chemical analysis.

The molecular formula of $\mathbf{1}$ was determined to be $\mathrm{C}_{57} \mathrm{H}_{87} \mathrm{O}_{24}$ from its HR-ESI-MS data ([M$\mathrm{H}]^{-} m / z, 1155.5589$ ) and ${ }^{13} \mathrm{C}$ NMR spectrum (Table 1). Similar to the saponins previously reported from the genus Aesculus, the NMR data of 1 displayed signals of a 30-carbon olean-12ene type aglycone, two five carbon side chains and a trisaccharide chain. Following detailed analyses of the NMR spectroscopic data (COSY, HSQC, HMBC and NOESY) and comparison with literature data, the triterpenoid skeleton was identified as protoaescigenin or $3 \beta, 16 \alpha, 21 \beta, 22 \alpha, 24,28$-hexahydroxyolean-12-ene as in compounds $\mathbf{6}$ and $\mathbf{1 3}$ (Voutquenne et al., 2005; Zhang and Li, 2007). The relatively high field shift of the $\mathrm{H}-23$ methyl signal at $\delta_{\mathrm{H}} 0.66$ and downfield shift of C-3 at $\delta_{\mathrm{C}} 91.2$ indicated a C-24 hydroxylation. The relatively high field shift of $\mathrm{H}-7\left(\delta_{\mathrm{H}}, 1.27,1.55\right)$ and the relatively low field shift observed for methyl in position 27 $\left(\delta_{\mathrm{H}} 1.85\right.$ and $\delta_{\mathrm{C}} 27.6$, respectively) revealed no hydroxyl substitution at C-15 but oxygen bearing 
at C-16. There were two sets of tigloyl group signals in ${ }^{1} \mathrm{H}-\mathrm{NMR}$ spectra of $\mathbf{1}\left(\delta_{\mathrm{H}} 7.07(1 \mathrm{H}, q, J\right.$ $=7.1), 1.63(3 \mathrm{H}, d, J=7.1)$, and $1.93(3 \mathrm{H}, s)$ and $\delta_{\mathrm{H}} 6.95(1 \mathrm{H}, q, J=7.1), 1.45(3 \mathrm{H}, d, J=7.1)$, and $1.84(3 \mathrm{H}, s)$, respectively). By analysis of COSY, HSQC, and HMBC spectra, the signals of the two tigloyl groups were assigned unambiguously at C-21 and C-22, respectively. The presence of trisaccharide residues were indicated by three anomeric proton signals at $\delta_{\mathrm{H}} 4.94(1 \mathrm{H}$, $d, J=7.2 \mathrm{~Hz}), 5.52(1 \mathrm{H}, d, J=7.0 \mathrm{~Hz}), 6.08(1 \mathrm{H}, b r s)$ and the corresponding anomeric carbons at $\delta_{\mathrm{C}} 104.2,103.3$, and 110.7. Acid hydrolysis of 1 afforded D-glucuronic acid, D-glucose and Larabinose as analyzed following aldose derivatization and HPLC analysis (Tanaka et al., 2007; Yuan et al., 2013). By HSQC, DQF-COSY, HMBC and 2D-TOCSY, it was possible to characterize one $\beta$-glucuronopyranosyl, one $\beta$-glucopyranosyl and one $\alpha$-arabinofuranosyl moieties. The glucuronic acid was determined to be in pyranose form from the ${ }^{13} \mathrm{C}$ NMR spectroscopic data. The $\beta$-anomeric configuration of glucuronic acid was determined according to the ${ }^{3} J_{\mathrm{H} 1}$, 2 coupling constants $(1 \mathrm{H}, d, J=7.2)$. The D-glucopyranosyl was determined to be in $\beta$-pyranose form according to its ${ }^{13} \mathrm{C}$-NMR spectroscopic data and ${ }^{3} J_{\mathrm{H} 1}$, $\mathrm{H}_{2}$ coupling constant $(1 \mathrm{H}$, $d, J=7.0$ ). The ${ }^{1} \mathrm{H}$-NMR and ${ }^{13} \mathrm{C}$-NMR signal assignments of $\alpha$-arabinofuranosyl were in accordance with those of previous reported Aesculus saponins. The HMBC correlation of glucuronic acid anomeric protons at $\delta_{\mathrm{H}} 4.94(1 \mathrm{H}, d, J=7.2 \mathrm{~Hz})$ with the downfield shift signal of C-3 at $\delta_{\mathrm{C}} 91.2$ established the linkage of glucuronic acid to C-3 of the aglycone. The attachment of D-glucopyranosyl and L-arabinofuranosyl to C-2' and C-3' of D-glucuronopyranosyl acid were determined by their HMBC correlations, H-1 of Glc- $p$ and Ara- $f\left(\delta_{\mathrm{H}} 5.52\right.$ and 6.08$)$ to C-2' $\left(\delta_{\mathrm{C}} 78.0\right)$ and C-3' $\left(\delta_{\mathrm{C}} 86.3\right)$ of GlcA, respectively. Therefore, the structure of $\mathbf{1}$ was assigned as 3-O-[ $\beta$-D-glucopyranosyl-( $(1 \rightarrow 2)]-\alpha$-L-arabinofuranosyl-( $1 \rightarrow 3)-\beta$-D-glucuronopyranosyl-21,22-

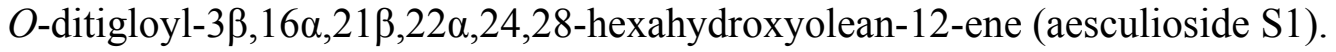


Compound 2 was assigned a molecular formula of $\mathrm{C}_{57} \mathrm{H}_{87} \mathrm{O}_{24}$ from its negative HR-ESI-MS ion peak at $m / z 1155.5583[\mathrm{M}-\mathrm{H}]^{-}$, same as aesculioside $\mathrm{S} 1(\mathbf{1})$. By detailed analysis and comparison of ${ }^{1} \mathrm{H}$ NMR, ${ }^{13} \mathrm{C}$ and HSQC spectra, the signals of $\mathbf{2}$ were almost superimposable to those of 1 in terms of the triterpenoid aglycone and oligosaccharide side chain. The trisaccharide groups of $\mathbf{2}$ were also confirmed as D-glucuronic acid, D-glucose and L-arabinose by acid hydrolysis and HPLC analysis. Compared with 1, one of the tigloyl groups apparently disappeared in 2 . The ${ }^{1} \mathrm{H}-\mathrm{NMR}$ spectra of $\mathbf{2}$ showed a set of characteristic angeloyl signals at $\delta_{\mathrm{H}}$ $5.87(1 \mathrm{H}, q, J=7.1 \mathrm{~Hz}), 2.03(3 \mathrm{H}, d, J=7.1 \mathrm{~Hz})$, and $1.89(3 \mathrm{H}, s)$. The angeloyl groups were established as C-22 substitution by HMBC correlations of angeloyl carboxyl carbons at $\delta_{\mathrm{C}} 168.5$ with the corresponding $\mathrm{H}-22$ at $\delta_{\mathrm{H}} 6.40(3 \mathrm{H}, d, J=10.2 \mathrm{~Hz})$. The structure of 2 was then elucidated as 3-O-[ $\beta$-D-glucopyranosyl- $(1 \rightarrow 2)]-\alpha$-L-arabinofuranosyl- $(1 \rightarrow 3)-\beta-\mathrm{D}-$ glucuronopyranosyl-21-O-tigloyl-22-O-angeloyl-3 $\beta, 16 \alpha, 21 \beta, 22 \alpha, 24,28$-hexahydroxyolean-12ene (aesculioside S2).

Aesculioside S1 (1) and S2 (2) were evaluated for their cytotoxicity against human lung adenocarcinoma epithelial cell (A549) and human prostate cancer cells (PC3). Aesculioside S1 (1) exhibited cytotoxic activity against A549 and PC3 with $\mathrm{GI}_{50}$ values of $18.2 \pm 4.3$ and 13.6 \pm 2.1 $\mu \mathrm{M}$, respectively (doxorubicin as positive control, $\mathrm{GI}_{50}$ against $\mathrm{A} 549$ and $\mathrm{PC} 3$ for $0.58 \pm 0.04$ and $0.81 \pm 0.06 \mu \mathrm{M}$, respectively). The cytotoxicity of Aesculioside S2 (2) against A549 and PC3 was evaluated at $\mathrm{GI}_{50}$ values of $11.7 \pm 1.3$ and $8.7 \pm 2.5 \mu \mathrm{M}$, respectively. The cytotoxicity data of these polyhydroxyoleanene saponins are consistent with the similar compounds isolated from A. pavia and A. glabra (Yuan et al., 2012; Zhang and Li, 2007; Zhang et al., 2006).

Our previous investigations found that the structures of triterpenoid saponins isolated from $A$. pavia and A. glabra of the section Pavia in eastern North America can be easily distinguished 
from those from other sections of Aesculus in Asia, Europe and western North America and all saponins in these two species are characterized by trisaccharide chains with an arabinofuranosyl unit fixed to C-3 of the glucuronopyranosyl unit (Yuan et al., 2012; Zhang et al., 2010). A. sylvatica is usually placed in the section Pavia with A. pavia, A. glabra, and A. flava distributed in the same region. All 16 saponins isolated from A. sylvatica have an arabinofuranosyl unit affixed to C-3 of the glucuronopyranosyl unit in the trisaccharide chain. This result supports the placement of A. pavia, A. glabra, and A. sylvatica under the same Pavia section.

As reported before, all the saponins in A. glabra have no hydroxyl group at C-24 (Yuan et al., 2012). However, saponins in both A. sylvatica and A. pavia have either hydroxyl or no hydroxyl group at C-24. Based on analysis of the saponin structures, $A$. sylvatica may be positioned more closely to A. pavia than to A. glabra within the Pavia section (Fig. 2). This phylogenetic relationship among A. pavia, A. glabra, and A. sylvatica drawn from the saponin structure similarity agrees with the phylogeny derived from combined analysis of internal transcribed spacer (ITS) sequence and morphological dataset (Xiang et al., 1998). In a more recent reconstructed phylogeny inferred from a combination of DNA sequence ( $L F Y$, trnHK, rps 16 , matK and ITS), morphology and fossil information, A. pavia, A. glabra, and A. sylvatica were still placed in the same eastern North America section Pavia. However, within the section Pavia, A. pavia was placed as the sister of the group of A. sylvatica and A. glabra (Harris et al., 2009). More new emerging data contribution seemed to make the taxonomy of Aesculus genus more complicated and controversial at this point. Further investigations are needed to resolve the long time taxonomy controversy.

Saponins from A. californica have more diversified structures which share more similar features to eastern Asian species than to eastern North American species (Yuan et al., 2013). 
This chemical evidence agrees to its closer relationship to the Asian clade in phylogeny derived from DNA and morphology data (Harris et al., 2009). According to analysis of the saponins isolated from Aesculus to date, we expect that A. flava in the section Pavia have similar saponins with the other species in the same section. Due to their distinctive morphological features, other two American Aesculus species, A. parviflora Walter and A. parryi A. Gray are usually placed into two different monotypic sections Macrothyrsus and Parryana, respectively. The chemical investigation of these two species will provide important clues to understand the systematics and evolutionary pattern of the genus Aesculus.

\section{Experimental}

\subsection{General experimental procedures}

NMR experiments were performed on a JEOL ECS 400 spectrometer, with spectroscopic data referenced to the solvent used. HR-mass spectra were acquired using a Waters Q-Tof Premier mass spectrometer. HPLC analysis was performed on an Agilent 1260 HPLC system using Agilent ODS columns (Column A: Poroshell 120 EC-C18, 2.7 $\mu \mathrm{m})$. Preparative HPLC was performed with a Lab-Alliance Series III Isocratic HPLC System using an Alltima C18 column (Column B: $250 \times 22 \mathrm{~mm}, 10 \mu \mathrm{m}$, Grace).

\subsection{Plant material}

Seeds of A. sylvatica were collected from Georgia, USA in 2012. The plant sample was identified by Dr. Shiyou Li and the voucher specimen (Ga-Fayetteville-NNN-10122012-AS-Fr) was deposited at the National Center for Pharmaceutical Crops at Stephen F. Austin State University, USA. 


\subsection{Extraction and isolation}

The seeds of A. sylvatica (400 g, dry weight) were ground to a coarse powder using a Thomas Model 4 Wiley ${ }^{\circledR}$ Mill. The powder was percolated with $4 \mathrm{~L}$ methanol using a $75 \times 600$ mm glass column. After evaporated under reduced pressure, the methanol extracts were pooled, concentrated and partitioned with $n$-hexane to remove compounds of low polarity ( $n$-hexane phase, $7 \mathrm{~g}$ ). The lower layer extracts were dried to give $19 \mathrm{~g}$ powder as the raw saponin fraction. The raw saponin was ground and mixed with $30 \mathrm{~g}$ octadecyl-functionalized silica gel $\left(\mathrm{C}_{18}\right)$ and loaded onto a pre-equilibrated open ODS column $(75 \times 200 \mathrm{~mm})$. The column was eluted with $45 \%, 65 \%, 80 \%$ and $100 \%$ methanol in water (each for $1 \mathrm{~L}$ ). The eluents were collected with a Spectra/Chrom CF-2 Fraction Collector (Houston, TX, USA) (50 mL for each fraction) and analyzed with Agilent 1260 HPLC (Column A: 45\% acetonitrile in 0.5\% HOAc water, 0.5 $\mathrm{mL} / \mathrm{min}, 210 \mathrm{~nm}$ ). Sub-fractions were subjected for further preparative HPLC separation according to the analysis results. The sub-fractions 7-9 were combined and separated by preparative HPLC system (column B, 40\% acetonitrile in $0.5 \%$ HOAc water, $3 \mathrm{~mL} / \mathrm{min}, 210 \mathrm{~nm}$ ) to yield 3 (54.3 $\mathrm{min}, 3.7 \mathrm{mg}$ ) and 4 (65.0 $\mathrm{min}, 6.3 \mathrm{mg}$ ). The sub-fractions 21-25 furnished 5 (54.3 min, $2.8 \mathrm{mg}$ ) and 6 (65.0 min, $7.1 \mathrm{mg}$ ) (column B, 46\% acetonitrile in 0.5\% HOAc water, 3 $\mathrm{mL} / \mathrm{min}, 210 \mathrm{~nm}) .7(54.3 \mathrm{~min}, 11.4 \mathrm{mg})$ and $8(65.0 \mathrm{~min}, 7.1 \mathrm{mg})$ were isolated from the subfractions 28 and 29 by preparative HPLC system (column B, $46 \%$ acetonitrile in $0.5 \%$ HOAc water, $3 \mathrm{~mL} / \mathrm{min}, 210 \mathrm{~nm}$ ). The sub-fractions $32-33$ were combined and separated by a preparative HPLC system (column B, 50\% acetonitrile in $0.5 \%$ HOAc water, $3 \mathrm{~mL} / \mathrm{min}, 210 \mathrm{~nm}$ ) to afford 9 (50.8 $\mathrm{min}, 7.4 \mathrm{mg}), \mathbf{1 0}(53.4 \mathrm{~min}, 8.6 \mathrm{mg}), \mathbf{1 1}(57.3 \mathrm{~min}, 9.6 \mathrm{mg})$ and $\mathbf{1 2}(60.5 \mathrm{~min}$, $7.5 \mathrm{mg}) .1$ (55.1 min, $10.4 \mathrm{mg}), 2$ (57.8 $\mathrm{min}, 11.7 \mathrm{mg})$, and 13 (60.7 $\mathrm{min}, 8.0 \mathrm{mg}$ ) were prepared from sub-fraction 35 by preparative HPLC system (column B, 53\% acetonitrile in $0.5 \%$ HOAc 
water, $3 \mathrm{~mL} / \mathrm{min}, 210 \mathrm{~nm}$ ). The sub-fraction 39 give 14 (56.3 min, $6.3 \mathrm{mg}), \mathbf{1 5}$ (59.8 min, 12.8 $\mathrm{mg}$ ), and 16 (64.9 min, $4.6 \mathrm{mg}$ ) by using preparative HPLC (column B, 55\% acetonitrile in $0.5 \%$ HOAc water, $3 \mathrm{~mL} / \mathrm{min}, 210 \mathrm{~nm}$ ).

3.4 3-O-[ $\beta$-D-glucopyranosyl-( $(1 \rightarrow 2)]-\alpha$-L-arabinofuranosyl-( $1 \rightarrow 3)-\beta$-D-glucuronopyranosyl21,22-O-ditigloyl-3 $\beta, 16 \alpha, 21 \beta, 22 \alpha, 24,28$-hexahydroxyolean-12-ene (aesculioside S1, 1)

White amorphous powder; $[\alpha]^{20}{ }_{\mathrm{D}}+17.2(\mathrm{c} 0.12, \mathrm{MeOH})$; For ${ }^{1} \mathrm{H}$ NMR and ${ }^{13} \mathrm{C}$ spectroscopic data, see Table 1; HRESIMS: $m / z 1155.5589[\mathrm{M}-\mathrm{H}]^{-}$(calcd. for $\mathrm{C}_{57} \mathrm{H}_{87} \mathrm{O}_{24}, 1155.5587$ ).

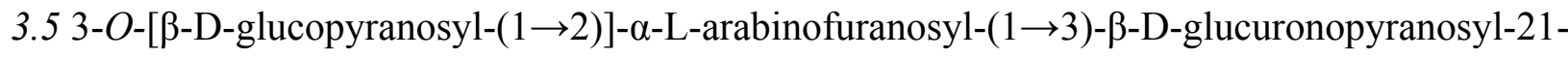
$O$-tigloyl-22-O-angeloyl-3 $\beta, 16 \alpha, 21 \beta, 22 \alpha, 24,28$-hexahydroxyolean-12-ene (aesculioside $\mathrm{S} 2,2$ )

White amorphous powder; $[\alpha]^{20}{ }_{\mathrm{D}}+11.7(\mathrm{c} 0.13, \mathrm{MeOH})$; For ${ }^{1} \mathrm{H}$ NMR and ${ }^{13} \mathrm{C}$ spectroscopic data, see Table 1; HRESIMS: $m / z 1155.5583[\mathrm{M}-\mathrm{H}]^{-}$(calcd. for $\mathrm{C}_{57} \mathrm{H}_{87} \mathrm{O}_{24}, 1155.5587$ ).

\subsection{Acid hydrolysis of new saponins aesculioside S1 (1) and S2 (2) and determination of absolute} configuration of sugars

Acid hydrolysis of aesculioside S1 (1) and S2 (2) and sugar determination followed a method described before (Tanaka et al., 2007; Yuan et al., 2013). By retention time comparison and coHPLC, the absolute configuration of sugars in each hydrolysis was identified as D-glucose, LArabinose and D-Glucuronic acid (Rt observed at 15.1, 16.3 and 17.9 min, respectively).

\subsection{Cytotoxicity assays}


The cytotoxicity assays were performed using a Cell Counting Kit-8 (CCK-8) (Dojindo Laboratories, Kumamoto, Japan) as previously described (Wang et al., 2010). Cytotoxicity was reported as $\mathrm{GI}_{50}\left(\mathrm{GI}=\left[1-\left(\mathrm{T}_{\mathrm{D}}-\mathrm{T}_{0} / \mathrm{T}_{\mathrm{C}}-\mathrm{T}_{0}\right)\right] \quad 100 . \mathrm{T}_{0}\right.$ was the initial reading before the treatment. $\mathrm{T}_{\mathrm{C}}$ or $\mathrm{T}_{\mathrm{D}}$ represents the readings of the untreated control or with the tested compounds. Doxorubicin was used as the positive cytotoxicity control ( $\mathrm{GI}_{50}$ against $\mathrm{A} 549$ and PC3 for $0.58 \pm 0.04$ and $0.81 \pm 0.06 \mu \mathrm{M}$, respectively).

\section{Acknowledgments}

This study was funded by USDA grants (2008-38928-19308 and 2009-38928-19744).

The NMR spectral analysis was conducted using a JEOL ECS-400 NMR spectrometer purchased through the Research Development Program at Stephen F. Austin State University. The authors would like to thank Vic Parcell of University of Iowa for HRESI-MS analysis; Dr. David Kulhavy of Stephen F. Austin State University for reviewing the manuscript. 


\section{References}

Chan, P.K., Zhao, M., Che, C.T., Mak, E., 2008. Cytotoxic acylated triterpene saponins from the husks of Xanthoceras sorbifolia. J. Nat. Prod. 71, 1247-1250.

Harris, A., Xiang, Q.Y., 2009. Estimating ancestral distributions of lineages with uncertain sister groups: a statistical approach to Dispersal-Vicariance Analysis and a case using Aesculus L.(Sapindaceae) including fossils. J. Syst. Evol. 47, 349-368.

Harris, A., Xiang, Q.Y., Thomas, D.T., 2009. Phylogeny, origin, and biogeographic history of Aesculus L.(Sapindales)-an update from combined analysis of DNA sequences, morphology, and fossils. Taxon. 58, 108-126.

Modliszewski, J.L., Thomas, D.T., Fan, C., Crawford, D.J., Xiang, Q.Y., 2006. Ancestral chloroplast polymorphism and historical secondary contact in a broad hybrid zone of Aesculus (Sapindaceae). Am. J. Bot. 93, 377-388.

Tanaka, T., Nakashima, T., Ueda, T., Tomii, K., Kouno, I., 2007. Facile discrimination of aldose enantiomers by reversed-phase HPLC. Chem. Pharm. Bull. 55, 899-901.

Voutquenne, L., Guinot, P., Froissard, C., Thoison, O., Litaudon, M., Lavaud, C., 2005.

Haemolytic acylated triterpenoid saponins from Harpullia austro-caledonica. Phytochemistry. 66, 825-835.

Wang, P., Ownby, S., Zhang, Z., Yuan, W., Li, S., 2010. Cytotoxicity and inhibition of DNA topoisomerase I of polyhydroxylated triterpenoids and triterpenoid glycosides. Bioorg. Med. Chem. Lett. 20, 2790-2796.

Xiang, Q.Y., Crawford, D.J., Wolfe, A.D., Tang, Y.C., Depamphilis, C.W., 1998. Origin and biogeography of Aesculus L.(Hippocastanaceae): a molecular phylogenetic perspective. Evolution. 988-997.

Yuan, W., Wang, P., Deng, G., Li, S., 2012. Cytotoxic triterpenoid saponins from Aesculus glabra Willd. Phytochemistry. 75, 67-77.

Yuan, W., Wang, P., Su, Z., Wang, V.S., Li, S., 2013. Cytotoxic triterpenoid saponins from husks of Aesculus californica (Spach) Nutt. Phytochemistry. 90, 95-105.

Zhang, Z., Li, S., 2007. Cytotoxic triterpenoid saponins from the fruits of Aesculus pavia L. Phytochemistry. 68, 2075-2086.

Zhang, Z., Li, S., Lian, X.Y., 2010. An overview of genus Aesculus L.: ethnobotany, phytochemistry, and pharmacological Activities.

Zhang, Z., Li, S., Zhang, S., Gorenstein, D., 2006. Triterpenoid saponins from the fruits of Aesculus pavia. Phytochemistry. 67, 784-794. 


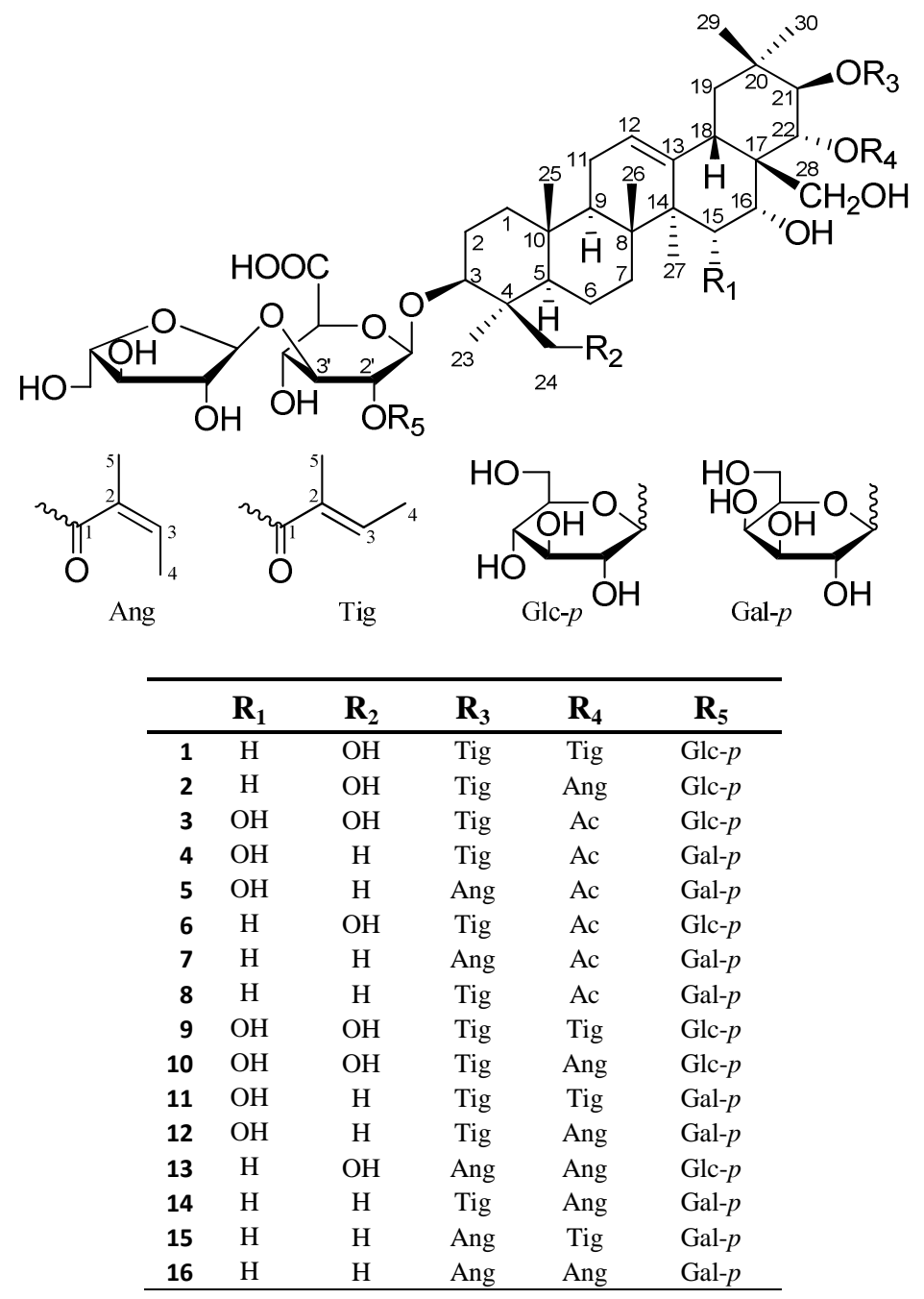

Fig. 1. The structures of triterpenoid saponins 1-16 from Aesculus sylvatica 


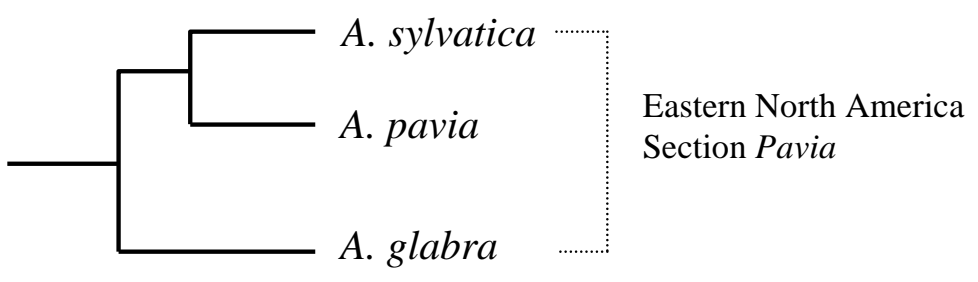

Fig. 2. The phylogenic relationship among three eastern North America Aesculus species $A$. pavia, A. glabra, and A. sylvatica derived from their saponin structure data 
Table1. ${ }^{1} \mathrm{H}$ NMR and ${ }^{13} \mathrm{C}$ NMR spectroscopic data for compounds $\mathbf{1 - 2}$ (400 MHz in pyridine- $d_{5}$ )

\begin{tabular}{|c|c|c|c|c|}
\hline & \multicolumn{2}{|l|}{$\mathbf{1}$} & \multicolumn{2}{|l|}{2} \\
\hline & $\delta_{\mathrm{H}}$ & $\delta_{\mathrm{C}}$ & $\delta_{\mathrm{H}}$ & $\delta_{\mathrm{C}}$ \\
\hline 1 & $0.84 \mathrm{~m}, 1.36 \mathrm{~m}$ & 38.8 & $0.80 \mathrm{~m}, 1.37 \mathrm{~m}$ & 38.8 \\
\hline 2 & $1.96 \mathrm{~m}, 2.31 \mathrm{~m}$ & 26.6 & $1.91 \mathrm{~m}, 2.30 \mathrm{~m}$ & 26.9 \\
\hline 3 & $3.45(d d, 11.5,3.0)$ & 91.2 & $3.44(d d, 11.0,3.0)$ & 91.8 \\
\hline 4 & - & 43.7 & - & 43.7 \\
\hline 5 & $0.89 \mathrm{~m}$ & 55.7 & 0.88 & 56.3 \\
\hline 6 & $1.55 \mathrm{~m}$ & 18.3 & 1.53 & 18.9 \\
\hline 7 & $1.27 \mathrm{~m}, 1.55 \mathrm{~m}$ & 33.2 & $1.27,1.55$ & 33.5 \\
\hline 8 & - & 40.6 & - & 40.4 \\
\hline 9 & $1.69 \mathrm{~m}$ & 46.3 & 1.67 & 47.2 \\
\hline 10 & - & 37.2 & - & 36.7 \\
\hline 11 & $1.76 \mathrm{~m}, 1.86 \mathrm{~m}$ & 23.9 & $1.74 \mathrm{~m}, 1.84 \mathrm{~m}$ & 24.3 \\
\hline 12 & $5.44 \mathrm{brs}$ & 123.3 & $5.42 \mathrm{brs}$ & 123.9 \\
\hline 13 & - & 143.0 & - & 143.6 \\
\hline 14 & - & 41.5 & - & 41.8 \\
\hline 15 & $\begin{array}{c}1.64 m, 1.88(1 \mathrm{H}, \\
d, 10.0)\end{array}$ & 35.1 & $1.61 m, 1.82(1 \mathrm{H}, d$, & 35.2 \\
\hline 16 & $4.51 \mathrm{~m}$ & 68.7 & $4.51 \mathrm{~m}$ & 68.9 \\
\hline 17 & - & 48.6 & - & 48.4 \\
\hline 18 & $\begin{array}{l}3.13(d d, \\
13.1,2.9)\end{array}$ & 40.0 & $\begin{array}{l}3.13(d d, \\
13.6,3.2)\end{array}$ & 40.6 \\
\hline 19 & $\begin{array}{c}1.46 m, 3.16(t, \\
13.1)\end{array}$ & 47.2 & $\begin{array}{c}1.14 m, 3.31(t, \\
13.6)\end{array}$ & 47.8 \\
\hline 20 & - & 37.1 & - & 36.9 \\
\hline 21 & $6.74(d, 10.0)$ & 79.0 & $6.69(d, 10.2)$ & 79.5 \\
\hline 22 & $6.35(d, 10.0)$ & 73.5 & $6.40(d, 10.2)$ & 73.8 \\
\hline 23 & $1.37 s$ & 22.1 & $1.37 \mathrm{~s}$ & 22.6 \\
\hline 24 & $3.31,4.31(d, 11.0)$ & 63.1 & $3.32,4.31(d, 10.5)$ & 63.5 \\
\hline 25 & $0.66 s$ & 15.4 & $0.65 s$ & 15.9 \\
\hline 26 & $0.81 s$ & 16.9 & $0.81 s$ & 17.1 \\
\hline 27 & $1.85 s$ & 27.6 & $1.85 \mathrm{~s}$ & 28.0 \\
\hline 28 & $3.42,3.66(d, 11.0)$ & 63.1 & $3.44,3.67(d, 11.0)$ & 64.1 \\
\hline 29 & $1.14 \mathrm{~s}$ & 29.5 & $1.13 \mathrm{~s}$ & 29.9 \\
\hline 30 & $1.37 s$ & 20.1 & $1.35 s$ & 20.7 \\
\hline & & & & \\
\hline & & & & \\
\hline
\end{tabular}

\begin{tabular}{|c|c|c|c|c|}
\hline \multicolumn{3}{|c|}{1} & \multicolumn{2}{|l|}{2} \\
\hline & $\delta_{\mathrm{H}}$ & $\delta_{\mathrm{C}}$ & $\delta_{\mathrm{H}}$ & $\delta_{\mathrm{C}}$ \\
\hline $\mathrm{C}_{21}$ & \multicolumn{2}{|l|}{ Tig } & \multicolumn{2}{|c|}{ Tig } \\
\hline 1 & - & 168.4 & - & 168.2 \\
\hline 2 & - & 129.9 & - & 129.8 \\
\hline 3 & $7.07(q, 7.1)$ & 137.1 & $7.09(q, 7.0)$ & 137.1 \\
\hline 4 & $1.63(d, 7.1)$ & 14.5 & $1.64(d, 7.0)$ & 14.1 \\
\hline 5 & $1.93 s$ & 12.7 & $1.94 s$ & 12.9 \\
\hline $\mathrm{C}_{22}$ & \multicolumn{2}{|l|}{ Tig } & \multicolumn{2}{|c|}{ Ang } \\
\hline 1 & - & 168.8 & - & 168.5 \\
\hline 2 & - & 129.4 & - & 129.5 \\
\hline 3 & $6.95(q, 7.1)$ & 137.5 & $5.87(q, 7.1)$ & 136.6 \\
\hline 4 & $1.45(d, 7.1)$ & 14.0 & $2.03(d, 7.1)$ & 16.2 \\
\hline 5 & $1.84 s$ & 12.7 & $1.89 \mathrm{~s}$ & 21.3 \\
\hline $\mathrm{C}_{3}$ & \multicolumn{2}{|c|}{ GlcA- $p$} & \multicolumn{2}{|c|}{ GlcA- $p$} \\
\hline 1 & $4.94(d, 7.2)$ & 104.2 & $4.92(d, 7.4)$ & 105.1 \\
\hline 2 & $\begin{array}{c}4.27(d d, 8.9 \\
7.2)\end{array}$ & 78.0 & $\begin{array}{l}4.27(d d, \\
8.2,7.4)\end{array}$ & 78.5 \\
\hline 3 & $4.26(t, 8.9)$ & 86.3 & $4.27(t, 8.2)$ & 87.0 \\
\hline 4 & $4.50(t, 8.9)$ & 71.5 & $4.51(t, 8.2)$ & 72.0 \\
\hline 5 & $4.57(d, 8.9)$ & 77.1 & $4.58(d, 8.2)$ & 77.9 \\
\hline 6 & & 172.0 & & 172.1 \\
\hline $\mathrm{C}_{2}$ & \multicolumn{2}{|l|}{ Glc- $p$} & \multicolumn{2}{|c|}{ Glc- $p$} \\
\hline 1 & $5.52(d, 7.0)$ & 103.3 & $5.52(d, 7.0)$ & 104.0 \\
\hline 2 & $\begin{array}{c}4.08(d d, 9.0, \\
7.0)\end{array}$ & 75.2 & $\begin{array}{l}4.08(d d, \\
9.1,7.0)\end{array}$ & 75.6 \\
\hline 3 & $4.27(t, 9.0)$ & 78.0 & $4.27(t, 9.1)$ & 78.5 \\
\hline 4 & $\begin{array}{c}4.59(d d, 9.0 \\
8.7)\end{array}$ & 69.2 & $\begin{array}{c}4.58(d d, 9.1, \\
8.6)\end{array}$ & 69.7 \\
\hline 5 & $3.66 \mathrm{~m}$ & 78.0 & $3.66 \mathrm{~m}$ & 78.6 \\
\hline 6 & $\begin{array}{c}4.36 m, 4.48 \\
(d d, \\
10.9,7.3)\end{array}$ & 61.2 & $\begin{array}{c}4.35 \mathrm{~m}, \\
4.47(d d, \\
11.2,7.3)\end{array}$ & 61.9 \\
\hline $\mathrm{C}_{3^{\prime}}$ & \multicolumn{2}{|l|}{ Ara- $f$} & \multicolumn{2}{|c|}{ Ara- $f$} \\
\hline 1 & $6.08(b r s)$ & 110.7 & $6.08(b r s)$ & 111.8 \\
\hline 2 & $5.00 \mathrm{~m}$ & 83.5 & $5.00 \mathrm{~m}$ & 84.0 \\
\hline 3 & $4.81 \mathrm{brd}, 5.8$ & 77.1 & $\begin{array}{c}4.82 \mathrm{brd}, \\
5.6\end{array}$ & 78.0 \\
\hline 4 & $\begin{array}{l}4.89(t d, \\
5.8,3.4)\end{array}$ & 85.4 & $\begin{array}{l}4.89(t d, \\
5.6,3.4)\end{array}$ & 85.8 \\
\hline 5 & $\begin{array}{c}4.21(d d, \\
11.1,3.4), \\
4.36 \mathrm{~m}\end{array}$ & 62.2 & $\begin{array}{c}4.18(d d, \\
10.5,3.4), \\
4.34 \mathrm{~m}\end{array}$ & 62.9 \\
\hline
\end{tabular}




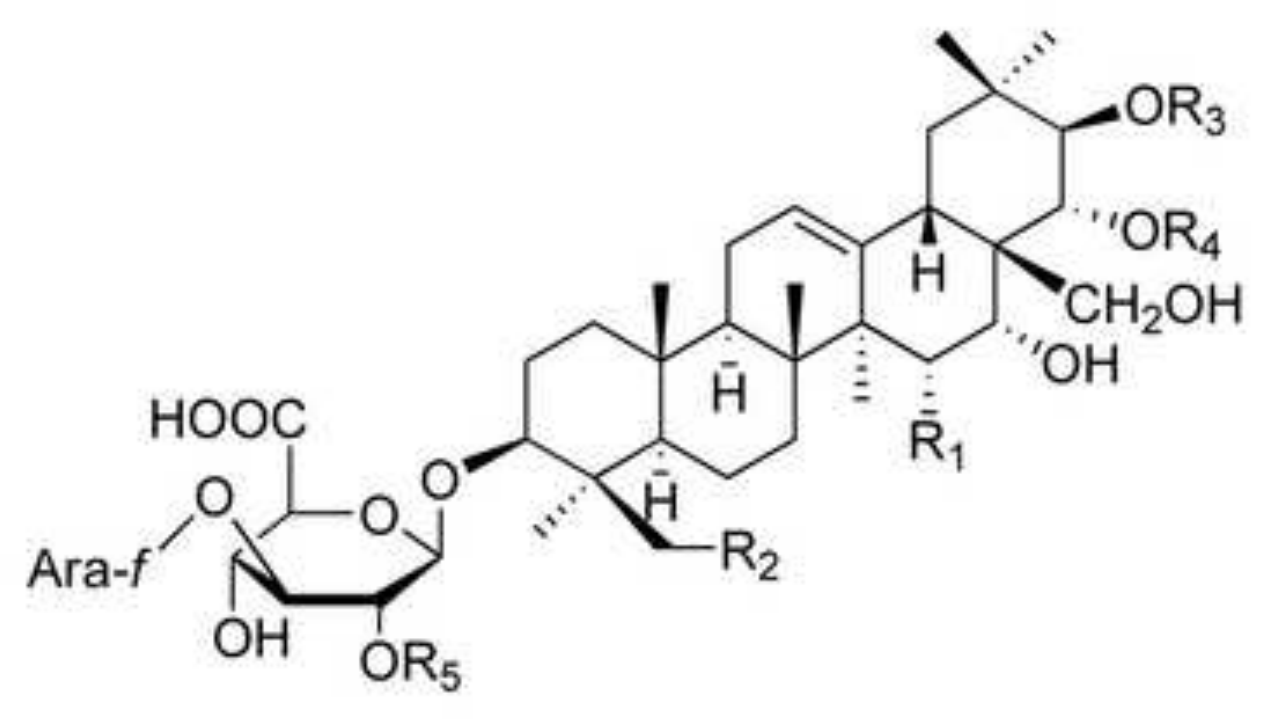

\begin{tabular}{|c|c|c|c|c|c|}
\hline & $\mathbf{R}_{1}$ & $\mathbf{R}_{2}$ & $\mathbf{R}_{3}$ & $\mathbf{R}_{4}$ & $\mathbf{R}_{5}$ \\
\hline 1 & $\mathrm{H}$ & $\mathrm{OH}$ & Tig & Tig & Gle $-p$ \\
\hline 2 & H & $\mathrm{OH}$ & Tig & Ang & Gle $-p$ \\
\hline 3 & $\mathrm{OH}$ & $\mathrm{OH}$ & Tig & $\mathrm{Ac}$ & Gle $-p$ \\
\hline 4 & $\mathrm{OH}$ & $\mathrm{H}$ & Tig & $\mathrm{Ac}$ & Gal $-p$ \\
\hline 5 & $\mathrm{OH}$ & $\mathrm{H}$ & Ang & $\mathrm{Ac}$ & Gal $-p$ \\
\hline 6 & $\mathrm{H}$ & $\mathrm{OH}$ & Tig & $\mathrm{Ac}$ & Glc $-p$ \\
\hline 7 & $\mathrm{H}$ & $\mathrm{H}$ & Ang & Ac & Gal-p \\
\hline 8 & $\mathrm{H}$ & $\mathrm{H}$ & Tig & $\mathrm{Ac}$ & Gal $-p$ \\
\hline 9 & $\mathrm{OH}$ & $\mathrm{OH}$ & Tig & Tig & Glcep \\
\hline 10 & $\mathrm{OH}$ & $\mathrm{OH}$ & Tig & Ang & Gle $-p$ \\
\hline 11 & $\mathrm{OH}$ & H & Tig & Tig & Gal- $p$ \\
\hline 12 & $\mathrm{OH}$ & $\mathrm{H}$ & Tig & Ang & Gal $-p$ \\
\hline 13 & H & $\mathrm{OH}$ & Ang & Ang & Glc.p \\
\hline 14 & H & $\mathrm{H}$ & Tig & Ang & Gal-p \\
\hline 15 & H & $\mathrm{H}$ & Ang & Tig & Gal-p \\
\hline 16 & $\mathrm{H}$ & $\mathrm{H}$ & Ang & Ang & Gal-p \\
\hline
\end{tabular}

